\title{
1968: memória dos atores e seus reflexos
}

\author{
Angélica Müller
}

Não há momento mais marcante na história do movimento estudantil brasileiro, e porque não dizer na história do movimento estudantil em todo mundo, que o "mágico" ano de 1968. Fatos como a "Passeata dos Cem Mil" são rememorados pelas gerações vindouras como expoente da capacidade de articulação e rebelião dos jovens estudantes.

O texto aqui descrito tem este duplo intuito: apresentar os acontecimentos de 68 através da memória daqueles que tiveram o papel central, os estudantes, e evidenciar e refletir sobre o significado desta memória que continua povoando o imaginário de muitos jovens.

Para tanto, a narrativa ganha destaque no desencadeamento do texto. Como bem constata Lucilia Neves Delgado (2003, p. 22), a narrativa como fonte para construção do conhecimento histórico tem um potencial inesgotável, pois é também instrumento de retenção do passado e, por conseqüência, suporte do olhar da memória.

O histórico aqui apresentado será construído através da narrativa realizada pelos principais expoentes da militância estudantil de 1968: Vladimir Palmeira, Jean Marc von der Weid, Franklin Martins, José Dirceu, Paulo de Tarso Venceslau, Bernardo Joffily e Cláudio Fonteles. Os depoimentos foram colhidos para o Projeto Memória do

* Doutoranda em História Social pela Universidade de São Paulo/Paris 1 - Pantheón Sorbonne. Bolsista do Colégio Doutoral Franco-Brasleiro/CAPES. 
Movimento Estudantil entre os anos de 2004 e 2005 e estão disponíveis em seu site. ${ }^{1}$

Segundo o historiador Daniel Aarão Reis, também importante militante da época, 1968 foi o ano de paixões desencadeadas em várias partes mundo. (Reis e Moraes, 1988). O ponto inicial e a confluência de todos esses movimentos estão na Guerra do Vietnã: a ofensiva do Tet, em janeiro, passou a acalentar idéias de que a união do povo e sua organização eram fatores fundamentais para o sucesso das idéias revolucionárias (quaisquer que fossem) e, a partir daí, os gritos por liberdade foram bradados em diferentes países nos quatro cantos do mundo.

Esses gritos ecoaram também no Brasil, mas a liberdade soou de maneira específica. Isso não quer dizer que o desenrolar dos processos internacionais não influenciaram na luta dos jovens estudantes brasileiros. No mundo inteiro, novos padrões de comportamento e modos de vida passaram a ser explorados. Mas, o apelo por mudanças comportamentais e culturais que tiveram grande importância no caso francês, e também no americano, surgia no Brasil como pano de fundo para uma ação centrada na política contra a ditadura militar vigente no país.

Depois do golpe militar de 1964, os estudantes levaram dois anos para se reorganizar, dando início à escalada rumo ao ápice do movimento de protesto de 68. Em 1966 foi realizado clandestinamente o Congresso da UNE e o movimento estudantil foi para as ruas protestar contra a política educacional. Dentre inúmeras manifestações, uma despertou comoção nacional: a invasão dos militares à Faculdade de Medicina na Praia Vermelha (Rio de Janeiro), que entrou para a história como o "Massacre da Praia Vermelha" porque a repressão agrediu brutalmente os estudantes.

Assim, estava configurada a conjuntura nacional que desencadearia nas lutas decisivas de 1968. O primeiro grande ato político deste ano no Brasil aconteceu no final de março, no Rio de Janeiro. No dia 31, os estudantes realizaram uma manifestação em defesa da permanência do

1 O trabalho de história oral realizado está baseado primordialmente nos estudos de Michel Pollak. Através das histórias de vida, buscamos recuperar dados sobre a história do movimento estudantil brasileiro, inexistentes em arquivos e em documentos de outra natureza, como os escritos e iconográficos. 
restaurante estudantil Calabouço, local de reuniões e mobilizações de estudantes. Como a ditadura queria fechá-lo, aconteceu um embate entre militares e estudantes culminando com a morte do estudante secundarista Edson Luís de Lima Souto. Vladimir Palmeira, presidente da União Metropolitana de Estudantes (UME) na época, lembra do acontecimento:

Uma primeira vítima mortal. Nós já tínhamos dito que um dia ia morrer estudante, sabíamos que ia morrer. Havia uma fronteira da polícia, e até onde ela chegaria? Foi um clima de grande indignação. Esse era o clima dominante da Assembléia. Nós passamos a noite na Assembléia e, no dia seguinte, foram os momentos mais bonitos do enterro do Edson Luís, quando começaram a chegar àqueles colégios de padres e de freiras [...] para visitar. Lançaram aquela palavra de ordem "Podia ser um filho seu", que foi uma palavra de ordem notável, que também não foi uma liderança que criou. Aquilo foi uma criação coletiva, alguém fez. Fizeram uma faixa, o pessoal gritava, foi criando aquele tom. Aquela manifestação impressionante, popular. (Depoimento de Vladimir Palmeira concedido ao Projeto Memória do Movimento Estudantil em 12/09/2005)

Um longo cortejo foi realizado, levando mais de cinqüenta mil pessoas do velório na Assembléia Legislativa até o cemitério São João Batista. Em todo país, várias manifestações ocorreram em conseqüência disso, ampliando o número de mortos e feridos. Na missa de sétimo dia, como forma de conter a pressão, o governo decretou ponto facultativo na cidade e o exército ocupou o centro levando a um novo choque entre estudantes e militares.

Toda imprensa deu ampla cobertura ao acontecimento, bem como aos demais que se seguiram. Uma das revistas de maior circulação na época, a Manchete trouxe na capa inteira da edição de 13 de abril a foto dos estudantes conduzindo o corpo de Édson Luis com os dizeres: "A morte de um estudante traumatiza o país". (Manchete, no 834, 13 abril de 1968, p. 4-13) Nove páginas foram dedicadas à matéria com inúmeras fotografias.

A comoção da morte de um estudante acabou não só por abalar a sociedade como também levou a uma mudança na forma de atuação, tanto dos estudantes, como dos militares. 
Jean Marc, presidente da UNE eleito em 1968, relembra que a morte de Edson Luis foi o marco do início das mobilizações de 1968. Partindo de uma questão ultra-específica, que era a resistência contra o fechamento do restaurante Calabouço, tornou-se uma questão muito mais ampla, de denúncia contra a violência, contra o arbítrio, contra a repressão, contra o regime. A partir daí conflitos armados e sangrentos ocorreram em todo o país nos meses seguintes.

Entre abril e maio o movimento repôs suas forças através de pequenas manifestações locais cujo principal tema era a crítica à política educacional do governo. Apresentavam reivindicações precisas e propunham o diálogo com o governo, diálogo esse que não tinha resposta. Conforme Daniel Aarão Reis, os dirigentes estudantis expressavam aspirações enraizadas no cotidiano de estudantes e professores (Reis e Moraes, 1988, p. 16).

As idéias de liberdade espalhadas por todo o mundo ganharam contorno específico no Brasil. A luta focada contra a política educacional do governo assumiu uma posição mais ampla, contra o regime. No final de junho, o movimento estudantil definiu-se pelo uso da violência. Decididos a se fazer ouvir pelo ministro da Educação, os estudantes resolveram ocupar o prédio do MEC no Rio de Janeiro. Estava instalado o palco para o episódio que ficou conhecido como a "quarta-feira sangrenta". Nesse dia foram construídas barricadas na avenida central da cidade e o choque com a polícia deu-se nesse mesmo lugar. Vladimir Palmeira relembra:

Quando a polícia veio, naquele passo terrível, largos, aqueles passos de ganso, disseram: "o que a gente faz?" Eu disse: "vamos resistir." Quando chegou, sei lá, a uns cinqüenta metros, a gente disse: "vamos para cima deles!" E fomos e batemos na polícia pela primeira vez. A polícia saiu correndo e nós atrás pelas aquelas ruelas do Centro, invertendo as coisas. Nós passamos quatro anos correndo deles. Dessa vez, eles estavam correndo da gente. Aí, pronto, virou uma batalha campal, porque mandaram a cavalaria e a gente jogou chimbra, bola de gude, rolhas. Cavalo caiu, menino andou em cavalo. Eu me lembro que teve um menino que botou um capacete da Polícia do Exército e montou no cavalo e saiu montado no cavalo. Houve de 
tudo. A massa é criativa. Até que tocaram fogo num caminhão do exército. Nesse momento, a barra pesou, chegou a Polícia do Exército e eu me mandei. O Jean Marc foi preso. Essa foi a Quarta-feira Sangrenta. (Depoimento de Vladimir Palmeira)

Nova passeata, em protesto ao ataque realizado no dia anterior, foi marcada para sexta-feira na Praça Tiradentes. Jean Marc, que estava preso no dia, conta o que os colegas lhe disseram:

Literalmente o Rio de Janeiro passou por uma insurreição, que foi o chamado dia da Sexta-feira Sangrenta, porque metade do grupo que estava em frente à embaixada [americana] correu para o centro da cidade e começou a montar barricada. [...] E, de repente, a população entrou no jogo. Quer dizer aquilo foi uma insurreição popular. Os estudantes foram o estopim do início daquela história, que só terminou às $20 \mathrm{~h}$ da noite. Teve um nível de violência, agressividade, de parte a parte, extremamente intenso. (Depoimento de Jean Marc von der Weid concedido ao Projeto Memória do Movimento Estudantil em 07/10/2004)

A seqüência de passeatas e conflitos brutais desembocou na grande "Passeata dos Cem Mil", realizada em 26 de junho. Por um momento, o regime recuou e permitiu a maior manifestação ocorrida durante a ditadura, que levou estudantes, artistas, intelectuais, religiosos e a população em geral a realizar uma passeata pacífica, apresentando denúncias contra o regime e reivindicações estudantis. Segundo Jean Marc, a origem de todo processo sobre verba, vagas nas universidades, privatização ou não privatização do ensino desapareceu frente a um novo conteúdo, que foi a luta contra o caráter repressivo do regime militar. Junto com a "Passeata dos Cem Mil", no Rio, na grande maioria dos Estados também houve manifestações. Este foi o momento culminante de 1968 no Brasil.

Como resultado da passeata foi eleita uma comissão para dialogar com o presidente Costa e Silva, chamada de "Comissão dos Cem Mil". Esta Comissão definiu uma pauta estritamente estudantil: mais verba para educação, reabertura do restaurante Calabouço e a soltura dos presos políticos. A negociação com o governo não foi adiante. Para Jean Marc, esta comissão cometeu um erro: "transformou uma manifestação de caráter 
libertário e democrático numa manifestação reivindicativa estudantil". (Depoimento de Jean Marc von der Weid)

Depois dessa grande passeata o movimento estudantil entrou num momento de refluxo. O segundo semestre de 1968 foi marcado principalmente pelas disputas internas no movimento, o que permitiu ao regime ganhar força contra os estudantes. Essas diferenças tornam-se explícitas na hora da disputa pela renovação dos quadros das entidades.

Foram duas as principais correntes que disputavam o movimento estudantil brasileiro nesse momento. Elas formaram dois grandes blocos: a Ação Popular (AP), força predominantemente estudantil derivada da JUC (Juventude Universidade Católica), que juntamente com partidos menores como o PCdoB (Partido Comunista do Brasil) e o PCBR (Partido Comunista Brasileiro Revolucionário) enfatizavam não só as denúncias políticas gerais contra o regime, mas também a luta contra o imperialismo e a solidariedade com os vietcongs. A AP, durante toda a década de 1960, elegeu o presidente da UNE e de outras entidades do movimento estudantil.

Já as dissidências do Partido Comunista, ${ }^{2}$ aliadas a Política Operária (POLOP) e em alguns casos ao PCB (Partido Comunista Brasileiro) acreditavam que o movimento estudantil deveria ser um instrumento de politização da luta contra a política educacional do governo. Nesse período, a "Dissidência da Guanabara" (Rio de Janeiro) e a de São Paulo ocuparam a presidência da UME (União Metropolitana de Estudantes) e da UEE/SP (União Estadual de Estudantes).

A disputa era acirrada e pode ser exemplificada pelo caso da UEE/ SP, que em seu Congresso de 1967 acabou por eleger duas diretorias, uma vinculada à $\mathrm{AP}$ e outra vinculada à Dissidência. Paulo de Tarso Venceslau, importante militante da "Dissidência" em São Paulo, lembra do episódio:

Quando a gente entra em 1968, a UEE tinha dois presidentes reconhecidos: a Catarina Melloni [AP] e o Zé Dirceu [Dissidência].

2 Como em outros países, desde o inicio da década de 1960, houve acirrada luta interna no PCB. Em 1967, com o VI Congresso do Partido, o grupo mais moderado liderado pelo secretário do Partido, Luis Carlos Prestes, obteve vitória das suas teses o que acabou por ser contestado por outros grupos mais ligados ao processo revolucionário cubano, gerando diversas dissidências partidárias. Ver: Ridenti e Reis Filho (org.), 2007. 
Os dois se proclamando presidente da UEE. Então, todo o movimento estudantil de 68 começa com esse clima em São Paulo, com dois presidentes. Você imagina a disputa que era em manifestação, quem fala, hora de falar, disputa de espaço, cotovelada daqui, pisa no pé de outro, um horror! Mas foi assim que o movimento explodiu em 1968. (Depoimento de Paulo de Tarso Venceslau concedido ao Projeto Memória do Movimento Estudantil em 14/06/2004)

Enquanto as entidades aparavam suas arestas, o regime tratou de "mostrar a que veio". Invasões de universidades, como a ocorrida na Universidade de Brasília (UnB), no Distrito Federal, em 30 de agosto, foram as preliminares dos tempos mais sombrios que estavam por vir. Cláudio Fonteles, militante da AP na UnB na época, conta como a Universidade era encarada pelos militares:

O estopim da invasão da UnB foi o paroxismo daquela concepção violenta do poder militar, traduzido naquela frase do coronel Meira Matos sobre os três pontos vermelhos. Para ele tinha no mundo: a Rússia, a China e a Universidade de Brasília. E eles queriam dar uma demonstração de força e de eliminação desse centro que entendiam como altamente perigoso. (Depoimento de Cláudio Fonteles concedido ao Projeto Memória do Movimento Estudantil em 11/06/2005)

Outro episódio que marcou profundamente o ano de 1968 foi o conflito da Rua Maria Antônia. Nesta rua estava localizada a Faculdade de Filosofia, Letras e Ciências Humanas da Universidade de São Paulo (USP), considerada "reduto" da esquerda em São Paulo e, em frente, a Universidade Presbiteriana Mackenzie, freqüentada por muitos alunos de direita (apesar da grande maioria dos Centros Acadêmicos e do Diretório Central dos Estudantes serem de esquerda). Segundo relato do líder estudantil José Dirceu, uma minoria daqueles estudantes tinham sido treinados pelo DOPS (Departamento de Ordem Política e Social).

O conflito teve início quando secundaristas realizavam um "pedágio" para coletar fundos para a UBES (União Brasileira de Estudantes Secundaristas). A partir de um determinado momento, esses alunos 
pasaram a ser agredidos por um grupo de estudantes do Mackenzie e procuraram proteção no prédio da Faculdade de Filosofia da USP. O conflito ganhou proporções maiores e acabou por resultar na morte do secundarista José Guimarães em 3 de outubro (Dirceu, 1999, p. 89). José Dirceu relembra:

Virou uma batalha campal, e de batalha campal, virou um ataque de ocupação. Falei assim: "Vai ser um massacre. Eles vão começar a matar estudantes, eles vão destruir, eles vão ocupar a faculdade”. Tanto é que isso aconteceu mesmo: a Força Pública deu cobertura para o DOPS e para as tropas de choque do Mackenzie para ocupar a faculdade e depois, juntos, destruíram a Maria Antônia inteirinha. Isso foi um dos atos mais trágicos de vandalismo e violência que houve na história política do Brasil! (Depoimento de José Dirceu concedido ao Projeto Memória do Movimento Estudantil em 17/12/2005)

Mas, o momento de maior tensão interna no movimento estudantil foi, sem dúvida, o famoso XXX Congresso da UNE, em Ibiúna, interior de São Paulo. A começar pela sua preparação. Em maio, a UNE realizou seu Conselho (uma espécie de reunião de diretoria) na cidade de Salvador. A discussão pelo formato do Congresso foi o cerne do encontro e serviu para encobrir a disputa das duas principais forças.

A correlação de forças dentro da Diretoria Executiva da UNE era muito equilibrada e, segundo Paulo de Tarso Venceslau, um membro da executiva é que revertia esta correlação. E isso parece ter se sucedido nesse Conselho. José Dirceu reafirma a questão: "Nós não tínhamos maioria no aparelho, não tínhamos maioria na organização porque não estávamos com a UNE (e eles estavam com a UNE há anos, tinham maioria)..." (Depoimento de José Dirceu).

No final, ficou referendado que a responsabilidade de definição do Congresso ficaria a cargo da diretoria da UNE. A AP queria que o Congresso se realizasse em Minas Gerais, onde controlava o movimento estudantil local. Mas, as Dissidências, através de votação, conseguiram levar o Congresso para São Paulo. Nessa mesma reunião ficou definido que uma "comissão de especialistas" trataria da data, local e toda infra-estrutura necessária para realização do Congresso. 
Esta comissão foi composta por membros da Dissidência de São Paulo que passaram a procurar um local para realização do Congresso. Com os confrontos quase que diários com a Polícia devido às manifestações de rua, a UEE/SP recebeu o apoio do General Zerbini (ex-comandante da Força Pública) que passava informações aos estudantes sobre a maneira de organização das tropas. Como a UEE não tinha um local para realização do Congresso, o General Zerbini ofereceu aos estudantes o sítio de seu ajudante de ordem, Simões, localizado na cidade de Ibiúna, mas que não oferecia infra-estrutura alguma.

As impressões sobre o Congresso são unânimes: Ibiúna foi um fracasso. Jean Marc relata que Ibiúna:

Foram cinco dias debaixo de chuva, num lugar extremamente desconfortável, que não estava preparado para receber mil pessoas, quer dizer, sem uma infra-estrutura para aquela demanda enorme de pessoas. Pessoas que levavam duas ou três horas em filas para conseguir comer um arroz papa com feijão duro. Um negócio realmente barra pesada; só mesmo uma paixão revolucionária para peitar aquele negócio. Fazia muito frio. Apesar de ser outubro fazia muito frio. Choveu muito, aquela chuvinha paulista, aquela chuva miúda que molhava e formava um lameiro, sem lugar para dormir. Foi, realmente, um negócio bastante pesado. E eu passei cinco dias discutindo com cada grupo de estudantes que chegava naqueles caminhões. Eu juntava o povo e discutia, discutia, discutia e discutia... (Depoimento de Jean Marc von der Weid)

A estrutura (ou a falta dela!) descrita por José Dirceu era a seguinte:

O local não tinha propriamente uma construção, era tudo feito de bambu; o plenário era de lona; não tinha instalações no refeitório. Infelizmente, hoje avalio que talvez não fosse possível fazer. Hoje, vejo que tínhamos que ter feito um congresso aberto e enfrentado a ditadura. Prendia todo mundo e fechava o local, entendeu? (Depoimento de José Dirceu)

Quando chegou a informação de que a repressão já tinha conhecimento do local e estava muito próxima, as discussões entre os dois 
principais grupos se intensificaram, não resultando em um ponto de convergência, o que facilitou a prisão dos quase mil estudantes, incluindo as principais lideranças do movimento estudantil. O fichamento de todos os estudantes presos serviu como um "banco de identificação" daqueles que entraram na luta armada e foram presos, torturados e muitos mortos pela ditadura.

Para além das críticas, poderíamos pensar também que Ibiúna foi a representação de toda tensão gerada naquele ano, seu "desaguadouro". A ebulição das movimentações estudantis em todo país carregavam em seu bojo as diferentes posições ideológicas que confluíam, respeitando cada matiz, no desejo do término da ditadura. Mas a luta interna e externa do movimento pode ter contribuído para o fortalecimento de outra luta interna: a da "linha-dura" do regime.

Depois de Ibiúna o movimento estudantil entrou num período de refluxo. Apesar de muitas lideranças presas, incluindo José Dirceu e Vladimir Palmeira, a diretoria da UNE resolveu fazer sua eleição em congressos regionais, que elegeram Jean Marc (que conseguiu escapar da prisão em Ibiúna) como seu novo presidente. Cabe salientar que apesar das diferenças entre grupos políticos, a representação da entidade conseguiu manter sua unidade.

Já com o movimento estudantil bastante desmobilizado, o ano de 1968 fecha com um último ato, ou melhor, com o Ato Institucional $n^{\circ} 5$, imposto pelo regime militar em 13 de dezembro. ${ }^{3}$

A violência que já estava sendo praticada nas ruas tomou uma forma muito mais ofensiva e muitos estudantes optaram pela luta armada, entrando para clandestinidade. A UNE continuou com seu trabalho em condições precárias e também na clandestinidade total. Assim termina o ano de 1968 para o movimento estudantil no Brasil.

Os ecos de 1968 espalhados por todo mundo perpassam ao longo dos anos e a memória daqueles eventos marca as gerações vindouras, levando àquilo que Michael Pollak (1992, p. 201) denominou de fenômeno de projeção ou identificação com determinado passado.

3 A historiadora Maria Paula Araújo (2007. p. 189) resume bem as principais bases do ato: O AI-5 fechou o Congresso Nacional por tempo indeterminado; cassou mandatos de deputados, senadores, prefeitos e governadores; decretou o estado de sítio; suspendeu o hábeas corpus para crimes políticos; cassou direitos políticos dos opositores do regime; proibiu a realização de qualquer tipo de reunião; criou a censura prévia. 
Bernardo Jofilly, que na época era vice-presidente da UBES, lembra de uma manifestação em prol do impeachment de Fernando Collor em 1992:

Eu estava vendo uma passeata [...] em São Paulo, e o rapaz do carro do som dizia que aquela passeata enorme, maravilhosa talvez até pudesse ser comparada à grande Passeata dos Cem Mil de 1968. Quando ele acabou de falar eu disse: - Rapaz, você está por fora! Vocês acabaram de fazer uma passeata três ou quatro vezes maior do que a Passeata do Cem Mil, essa que é a verdade. Vocês não precisam se envergonhar, jogar na retranca. Vocês estão fazendo uma coisa importante, que vai entrar para a história do movimento estudantil. Com essa campanha do Fora Collor vocês puseram minha geração no chinelo, do ponto de vista quantitativo, sem sombra de dúvida. (Depoimento de Bernardo Joffily concedido ao Projeto Memória do Movimento Estudantilem 08/11/2004).

Marieta Ferreira (apud Delgado, 2003, p. 17) aponta que a memória é a construção do passado pautada por emoções e vivências e que os eventos são lembrados à luz da experiência subseqüente e das necessidades do presente. Presente e passado se interpenetram. "Relembrar 68"4 significava resgatar um passado de luta que pudesse pautar a luta de então projetando novas possibilidades para o futuro.

Histórias relatadas e acontecimentos relembrados atravessam um tempo e são reconstruídos, trazendo a possibilidade de atualização do passado no presente. Gustavo Petta, presidente da UNE entre 2003-2007, rememora as histórias contadas por seu pai, também um ex-militante estudantil em 1968:

Foram várias histórias. Mas a mais marcante é a história do Congresso de Ibiúna [...]. O meu pai esteve presente no Congresso e também foi preso. A minha avó foi uma das líderes do movimento das mães que foram até a porta do Carandiru pedir a libertação

4 Não podemos deixar de levar em conta que o "clima 68" foi muito favorecido pela mini-série da Rede Globo Anos Rebeldes. 
dos filhos. Chorou, foi para o jornal, fez todo um movimento em torno daquela questão. E foi um movimento, inclusive, muito forte, o movimento das mães porque foram mais de 800 presos no Congresso... (Depoimento de Gustavo Petta concedido ao Projeto Memória do Movimento Estudantil em 11/11/2004)

Jeanne Marie Gagnebin (2006, p. 50), partindo de ensaios de Walter Benjamin, aponta a possibilidade de uma tradição compartilhada por uma comunidade humana, tradição retomada e transformada, em cada geração, na continuidade de uma palavra transmitida de pai para filho. A memória coletiva de 1968 relembrada passa fazer parte de um histórico pessoal, regressando mais uma vez ao "fenômeno de projeção" defendido por Pollak, gerando assim uma afirmação ainda maior para seu presente.

O ano de ouro do movimento estudantil é um ano mítico. Toda a geração 68 relembra dos acontecimentos mesmo sem os ter vivenciado no ato. É o que Pollak (1992, p. 21) define como "acontecimentos vividos por tabela", dos quais a pessoa nem sempre participou, mas que, no imaginário, tomaram tamanho relevo que, no fim das contas, é quase impossível que ela consiga distinguir se participou ou não. É um ano mítico porque as gerações vindouras se apropriam dele para pautar suas lutas no presente. É mítico e, às vezes, místico, pois a memória de 1968 é reconstruída passando a servir de "modelo" para orientar, "iluminar" os militantes do presente.

1968, o "ano das paixões desencadeadas", o "curto ano de todos os desejos", o "ano que não terminou", o ano da "paixão de uma utopia" enfim o ano que "mudou o mundo", 5 quarenta anos depois continua suscitando profundos debates e povoa, principalmente, a mente dos jovens universitários. Seja na dupla característica - do velho pelo novo, como afirmam alguns intelectuais (Morin, 1968; Touraine, 1968; Joffrin, 1988) no caso francês, ou na luta contra o regime instaurado no Brasil pelo golpe militar de 1964, o que fica marcado na memória e também na história é a "paixão revolucionária", atestada por Jean Marc, símbolo daqueles jovens que queriam mudar seu mundo.

5 Com exceção da primeira frase as demais que se seguem são títulos de artigos e livros de autores brasileiros, na ordem: Reis Filho, 1998; VENTURA, Zuenir. 1968: o ano que não terminou. Rio de Janeiro: Nova Fronteira, 2006. Reis Filho e Moraes, 1988; Alves, 1993. 


\section{Acervos pesquisados}

Centro de Documentação em História Contemporânea - CEDEM/UNESP

Projeto Memória do Movimento Estudantil (www.mme.org.br)

\section{Referências Bibliográficas}

ALVES, Márcio M. 68 mudou o mundo. Rio de Janeiro: Nova Fronteira, 1993.

ARAújO, Maria Paula. Memórias estudantis: da fundação da UNE aos nossos dias. Rio de Janeiro: Relume Dumará, 2007.

DELGADO, Lucília de A. Neves. História oral e narrativa: tempo, memória e identidades. História Oral. Revista da Associação Brasileira de História Oral. São Paulo, n. 6, p. 9-25, 2003.

DIRCEU, José. O movimento estudantil em São Paulo. In: GARCIA, Marco Aurélio. VIEIRA, Maria Alice (org.). Rebeldes e contestadores. 1968: Brasil, França e Alemanha. São Paulo: Fundação Perseu Abramo, 1999, p. 83-93.

GABNEBIN, Jeanne Marie. Lembrar escrever esquecer. São Paulo: Editora 34, 2006.

JOFFRIN, Laurent. Mai 68: Histoire des Événements. Paris: Éditions du Seuil, 1988.

MORIN, Edgar et alli. Mai 1968: la Brèche. Premières réflexions sur les événements. Paris: fayard, 1968.

POLLAK, Michael. Memória e identidade social. Revista Estudos Históricos. Rio de Janeiro, vol. 5 n. 10, 1992.

REIS FILHO, Daniel A. 1968: o curto ano de todos os desejos. Tempo Social: Revista de Sociologia da USP. Dossiê maio de 68. São Paulo, v. 10, n. 2, p. 25-35, outubro de 1998.

REIS FILHO, Daniel A.; MORAES, Pedro. 1968: a paixão de uma utopia. Rio de Janeiro: Espaço e Tempo, 1988.

RIDENTI, Marcelo; REIS FILHO, Daniel A. (org.). História do Marxismo no Brasil: partidos e movimentos após os anos 1960. Vol 6. Campinas: Unicamp, 2007.

TOURAINE, Alain. Le movement de mai on le communisme utopique. Paris: Éditions du Seuil, 1968.

VENTURA, Zuenir. 1968: o ano que não terminou. Rio de Janeiro: Nova Fronteira, 2006.

Resumo: O ano de 1968 entrou para história como um ano de grandes manifestações e transformações em todo mundo. A memória herdada de 68 continua evidente fazendo com que os acontecimentos vividos por aquela geração permaneçam no imaginário das próximas, induzindo ao que Michael Pollak denominou de fenômeno de projeção ou identificação com determinado passado. 
A idéia desta exposição é apresentar um histórico do ano de 1968 no Brasil narrado através da memória de seus principais atores: o movimento estudantil. E, através dela, evidenciar e refletir sobre o significado desta memória que, mesmo depois de quarenta anos, continua povoando as mentes de muitos jovens.

Palavras-chave: movimento estudantil brasileiro; 1968; Brasil: regime militar.

\section{8: memory of actors and its reflects}

Abstract: The year of 1968 entered to the history as an year of great manifestations and transformations throughout the world. The memory inherited from 1968 remains evident making the facts lived by that generation to still be present in the mind of the next ones, leading to that Michael Pollak called projection or identification with a specified pass phenomenon. The idea of this exposition is to present a report on the year of 1968 in Brazil, told by the memory of its main actors: the student movement. And, by means of this, to highlight and to reflect about the meaning of this memory, that even after forty years, remains in the mind of so many young people.

Keywords: Brazilian Student Movement; 1968; Brazil: military government. 